b. The drug administered groups:

(1) Cytochrome C. $0.0012 \mathrm{mg} / \mathrm{g} /$ day

(2) Solcoseryl $\quad 0.01 \mathrm{mg} / \mathrm{g} /$ day

(3) Predonin $\quad 0.004 \mathrm{mg} / \mathrm{g} /$ day

(4) CDP-choline $\quad 0.01 \mathrm{mg} / \mathrm{g} /$ day

c. The chemical inhalation groups:

(1) $70-80 \%$ axygen.

(2) $5-10 \%$ carbon dioxide.

(3) $50 \%$ oxygen, $3 \%$ carbon dioxide, $47 \%$ nitic gas.

2. The results of the experiments:

a. The administration of:

(1) Cytochrome $\mathrm{C}$. indicated significant affects on both the granulation of glycogen and the recovery of bioreaction.

(2) Solcoseryl indicated the affects on the granulation of glycogen appearing at a comparatively earlier stage than that of the contrast group, and moderate affects on the recovery of dioreation.

(3) Prednisolone indicated the affects on the granulation of glycogen to be significant, and although, the affects of on the action and reaction on the recovery of bioreaction were satisfactory, a delay was noticed in the asorption of food.

(4) CDP-choline indivated significant affects on both the granulation of glycogen and the recovery of bioreaction.

b. The inhalation of:

(1) Oxygen indicated significant affects on both the granulation of glycogen and the recovery of bioreaction.

(2) Carbon dioxide indicated significant affects on the granulation of glycogen, and moderate affects on the recovery of bioreaction.

(3) Mixed gas indicated significant affects on both the granulation of glycogen, and the recovery of bioreaction.

\title{
31. Artificial Hibernation in Neurosurgical Patients
}

\author{
Shigenobu TAKaYAMA \\ Neurosurgery, The First National Hospital, Tokyo
}

The author described techniques of our artificial hibernation, how hibernation acts to the lesions and results at our clinic.

The technique of artificial hibernation used is a combination of neuroplegia and mild hypothermia. 
For neuroplegia, "Lytic cocktail $\mathrm{M}_{1}$ " after Laborit (Wintermin $50 \mathrm{mg}$, Pyrethia $50 \mathrm{mg}$, Opistan $100 \mathrm{mg}$ ) is used with $500 \mathrm{ml}$ of $5 \%$ glucose solution as venous drop injection material. Neuroplegia increases the lowering of metabolism and has a specific effect on post-traumatic reactions (cerebral edema, increased intracranial pressure, anoxia and fever). It facilitates hypothermia as much as narcosis does but in a better way. It is preferable to narcosis in unconscious patients (still sensible to cold and apt to shiver) as it does not greatly deepen the level of unconsciousness. And it may be continued for several days, if necessary. We continued it for 660 days in one case until recovery.

For hypothermia, placing the patient in contact with several bags containing ice at head, neck, axillary groove and inguinal region is used. The degree of hypothermia obtained varies from a restoration of normal temperature to a lowering of rectal temperature to 35.5 to $36^{\circ} \mathrm{C}$.

51 cases (severe head injury 26 , postoperative hyperthermia 21 , and each one of apoplexy, encephalitis, postanoxic states and tetanus) were treated by our trtificial hibernation with good results except two deaths of head injury.

\title{
32. On the Formation of Membrane enclosing Epidural and Subdural Hematoma
}

\author{
Yoshiro TakeuchI \\ Neurosurgical Service, Handa City Hospital, Handa City
}

Chronic subdural hematoma was first considered to be of inflammatory origin and described as pachymeningitis interna chronica. In these days, many authors have though that this condition may arise after severe, trifling or even forgotten trauma. But Prof. Kondo reported in 1960 and 1965 that chronic subdural hematoma pertained to pachymeningitis hemorrhagica interna and was fundamentally different clinical entity from acute traumatic subdural hematoma.

In this report, 4 chronic subdural hematoma and 2 chronic epidural hematoma were reviewed. They were experienced in the neurosurgical service of Handa City Hospital between April, 1965 and September, 1966. Three cases gave us the important suggestions to mechanism of formation of the enclosing membrane.

A case of subdural hematoma, 16 years old boy, showed subarachnoid accumulation of xanthochromic fluid. Neomembrane was seen on the dural side, not on the arachoidal side, and bleeding was microspically observed in the arachnoid membrane at the border of hematoma.

Two cases of epidural hematoma had the inner and outer membranes, between 